\title{
Prevention Studies in Alzheimer's Disease: Progress Towards the Development of New Therapeutics
}

\author{
Nicola Coley ${ }^{1,2,3} \cdot$ Adeline Gallini $^{1,2,3} \cdot$ Sandrine Andrieu ${ }^{1,2,3}$
}

Published online: 19 July 2015

(c) Springer International Publishing Switzerland 2015

\begin{abstract}
Alzheimer's disease (AD) is the most common form of dementia and is a major cause of disability and dependency amongst older people. AD drugs approved so far are symptomatic treatments and are not thought to affect the underlying disease process. Trials conducted with agents aiming to slow or stop disease progression in patients with $\mathrm{AD}$ have all failed, perhaps because they were tested too late in the disease process. Therefore, there has been a move towards prevention of AD. This paper presents an overview of trials testing pharmacological interventions for sporadic AD prevention. Those tested to date were initially developed for the treatment of $\mathrm{AD}$ or for the treatment of other conditions, rather than being specifically developed for $\mathrm{AD}$ prevention. Associated issues, such as evidence of 'proof-of-concept,' doses and safety, are discussed. A major shift has taken place in the methodology of AD prevention trials since the results of the first trials were published in the 1990s. New directions that are currently being considered in ongoing or future prevention trials are discussed, in terms of endpoints, target populations, and study design. The use of AD-specific drugs to prevent $\mathrm{AD}$ in high-risk individuals is currently limited by a lack of validated predictive and surrogate markers. Population approaches, such as lifestyle changes,
\end{abstract}

N. Coley and A. Gallini contributed equally to this work.

Sandrine Andrieu

sandrine.andrieu@univ-tlse3.fr

Inserm UMR1027, 31073 Toulouse, France

2 University Toulouse III, 31073 Toulouse, France

3 Department of Epidemiology and Public Health, CHU Toulouse, 31073 Toulouse, France are an alternative strategy that could be of public health interest, but may provide only limited benefits for individuals. The best chance of preventing AD may come from a combination of individual and population prevention approaches.

\section{Key Points}

Following the failure of treatment trials in symptomatic Alzheimer's disease (AD), there has been a move towards prevention of $\mathrm{AD}$.

To date, no specific pharmacological intervention has been developed for sporadic AD prevention and trial results have been disappointing.

A major shift has taken place in the methodology of $\mathrm{AD}$ prevention trials and new directions are being considered in terms of endpoints, target populations, and study design.

\section{Introduction}

Alzheimer's disease (AD) is a progressive neurodegenerative disease that affects memory and other cognitive domains, and is the most common form of dementia. It is a major cause of disability and dependency amongst older people, and has a huge impact on both families and society. There were an estimated 36 million cases of $\mathrm{AD}$ and other dementias worldwide in 2010 , and this number is set to more than triple by 2050 due to demographic aging [1], 
despite suggestions of a decrease in their incidence in western countries [2-4]. The annual global cost of dementia is estimated at more than US\$600 billion [5].

The major pathological features of $\mathrm{AD}$ are cerebral plaques and neurofibrillary tangles, mainly comprised of $\beta$ amyloid $(\mathrm{A} \beta)$ and hyperphosphorylated tau, respectively. Other characteristics of this disease include synaptic dysfunction, neuronal and white matter loss, inflammation, and oxidative stress [6].

Drugs approved so far for $\mathrm{AD}$ are symptomatic treatments targeting cholinergic and glutamatergic neurotransmission and are not thought to affect the underlying disease process [7]. A number of phase III trials have been conducted using agents aiming to slow or stop disease progression (disease-modifying drugs), including six compounds, such as monoclonal antibodies or $\gamma$-secretase inhibitors, specifically targeting the amyloid cascade, but all have failed [8-12].

Various reasons may explain these failures. For instance, there may have been too much focus on $A \beta$, which may not be the right target for an effective $A D$ treatment [13-15], or the drugs tested so far may not have been targeting the right form of amyloid [16]. Furthermore, the AD subjects recruited to these trials may have been very heterogeneous and not all may have had evidence of amyloid plaques [17]. Finally, a widely held belief is that intervening at the dementia stage may be too late, and that putative disease-modifying agents, particularly anti-amyloid therapies, should be initiated earlier in the disease process [18-21]. The recent solanezumab trials provided some support to this theory, since there was a suggestion of beneficial treatment effects in patients with mild AD but not in those with moderate forms [22].

Indeed, the physiopathological changes associated with $\mathrm{AD}$ are thought to begin decades before the onset of clinical symptoms [23]. Because of this long asymptomatic phase, AD may be particularly amenable to prevention. Furthermore, epidemiological studies have identified numerous modifiable factors, such as diet, physical exercise, cognitive reserve and cardiovascular risk factors, which are associated with AD risk [24]. It has been estimated that a preventive intervention able to delay disease (dementia) onset by just 1 year could result in 9 million fewer cases by 2050 [25].

\section{Prevention Trials of Alzheimer's Disease (AD) with Pharmacological Agents}

This paper does not aim to give a systematic review of prevention trials of AD. Such a review can be found in recent papers (e.g. Williams et al. [26]). Here we briefly describe pharmacological approaches (excluding vitamins and supplements) that have been tested or are currently being tested to prevent sporadic AD (excluding trials in prodromal subjects). Essentially, two types of drugs have been tested for AD prevention: drugs specifically designed to treat $\mathrm{AD}$ and other drugs (see Table 1).

\subsection{AD-Specific Drugs}

Cholinesterase inhibitors (donepezil, galantamine, and rivastigmine) have been approved for the symptomatic treatment of AD since the late 1990s. In the following decade, these drugs were tested for $\mathrm{AD}$ prevention in randomized controlled trials (RCTs). Trials involved subjects with mild cognitive impairment (MCI) and showed possible positive effects on some but not all primary endpoints for donepezil [27-29] and rivastigmine [30]. However, to date, cholinesterase inhibitors are not approved for prevention. Trials with galantamine were negative [31, 32].

Among more recently developed AD-specific drugs, only one is currently being tested in sporadic AD prevention. The A4 Study plans to test the efficacy of solanezumab (a humanized monoclonal anti-A $\beta$ antibody) in 1000 clinically normal older individuals identified as at-risk for progression to AD dementia due to brain amyloid accumulation on positron emission tomography (PET) imaging [33]. Furthermore, some prevention trials are testing antiamyloid therapies in autosomal-dominant AD [34, 35].

\subsection{Other Pharmacological Interventions}

In accordance with $\mathrm{AD}$ risk factors and supposed physiopathology, observational studies have proposed that various drugs may be beneficial in AD prevention: antihypertensives [36, 37], hormone replacement therapy (HRT) [38, 39], non-steroidal anti-inflammatory drugs (NSAIDs) [40, 41], HMG-CoA reductase inhibitors (statins) [42-44], and antidiabetics [45]. All five therapeutic classes are very commonly used in the general population.

To confirm a hypothetical preventive effect on $\mathrm{AD}$, large RCTs have been or are being conducted. However, apart from antihypertensive trials to some extent [46, 47], they have not demonstrated a protective effect of the candidate drugs.

Trials are still being conducted and ongoing RCTs are testing the efficacy of oral conjugated estrogens or estradiol in 700 recently post-menopausal women (KEEPS Cog (Kronos early estrogen prevention study cognitive and affective substudy) trial [48]), and of aspirin in 19,000 older subjects (ASPREE [ASPirin in Reducing Events in the Elderly] trial [49]).

More recently, other drugs already approved for the treatment of other conditions have been proposed for AD prevention and are being tested in ongoing trials. 


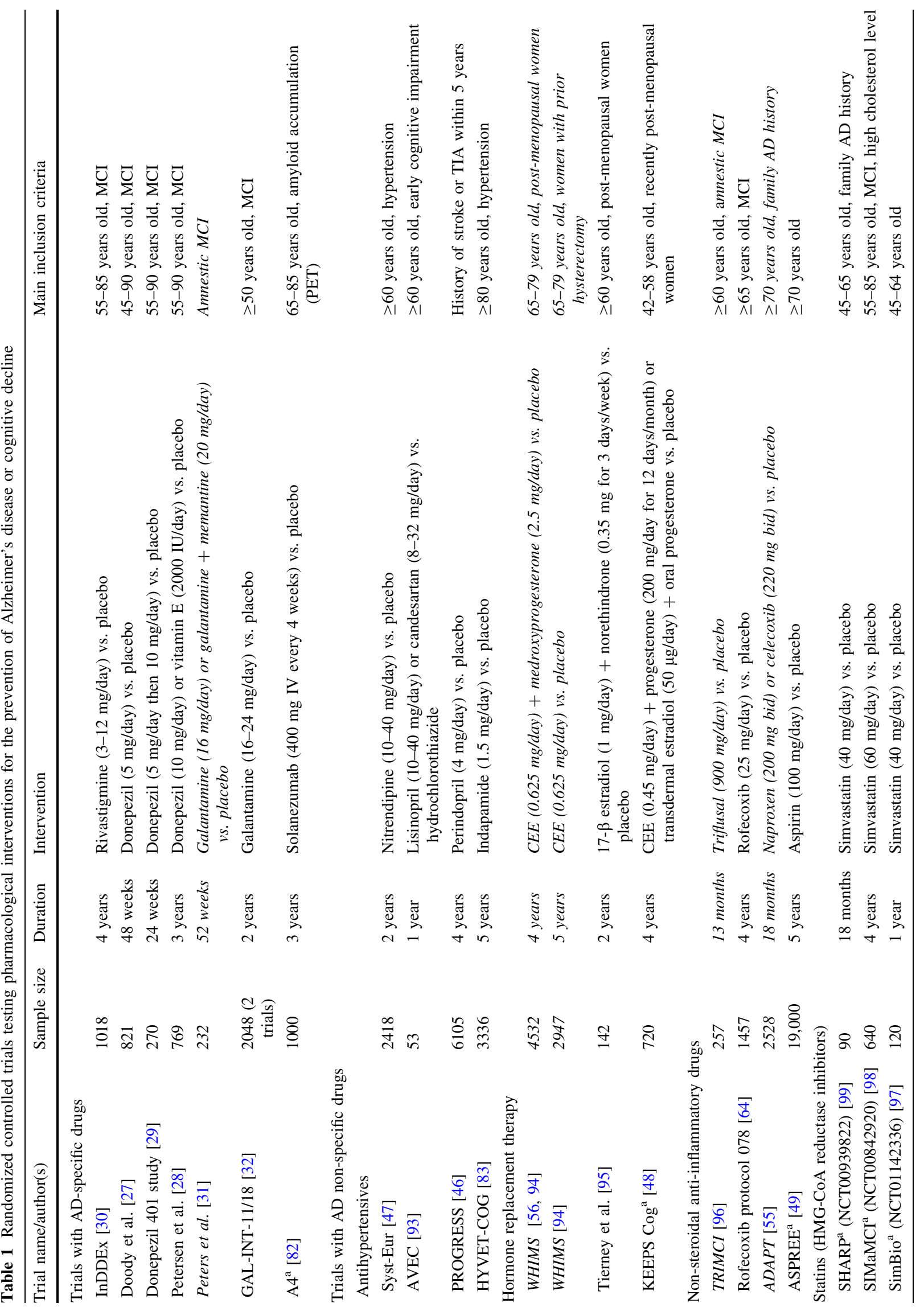


Despite no effect on disease progression in mild-tomoderate $\mathrm{AD}$ [12], three trials are currently investigating the efficacy of simvastatin on AD prevention in subjects with normal cognition (NCT01142336 [97]), MCI (NCT00842920 [98]), or with a parent with documented AD (NCT00939822 [99]). Proposed mechanisms of action for statins include a lipid-lowering action resulting in reduction of amyloid plaques, reduction of neurofibrillary tangles, and effects on inflammation and endothelial function [50].

Last, based on evidence of preclinical studies and from small AD treatment trials, pioglitazone is being tested for $\mathrm{AD}$ prevention in the ongoing TOMMOROW trial which plans to follow 5800 subjects for up to 5 years [51]. Only the subjects with the highest risk of developing MCI due to $\mathrm{AD}$ will be receiving pioglitazone. Mechanisms through which pioglitazone, a peroxisome proliferator-activated receptor- $\gamma$ (PPAR- $\gamma$ ) agonist approved in diabetes mellitus, is thought to be effective include action on inflammation, mitochondrial dysfunction, and amyloid burden [52, 53].

\section{Issues Related to the Re-Use of Existing Data}

So far, no pharmacological intervention has been specifically designed for sporadic AD prevention. Tested drugs were either developed for the treatment of $\mathrm{AD}$ or for the treatment of other conditions. The lack of phase II trials brings various issues that could have contributed to the mostly negative findings of prevention trials, similar to the critique that some phase III trials in treatment of $\mathrm{AD}$ were conducted based on insufficient evidence from phase II trials [8].

\subsection{Lack of 'Proof of Concept'}

For AD-specific drugs, 'proof of concept' relied on transposing findings from phase II and III treatment trials in AD patients to prevention trials based on the reasonable hypothesis that targets identified for treatment were relevant in prevention and that they may be more beneficial at earlier stages of disease development [19].

For other drugs, the 'proof of concept' only relied on preclinical and/or observational studies and on the fact that the pharmacodynamic mechanism was compatible with AD physiopathology. The traditional phase II of drug development was therefore skipped. Furthermore, the timing of exposure and doses and/or the pharmacological ingredient tested in intervention trials were not necessarily those identified in observational studies [54]. Disappointing results from very large phase III trials emphasize the need for phase II data. Indeed, in two RCTs, not only did the candidate drugs not prevent $\mathrm{AD}$, but, converse to the 
hopes brought by observational studies, their use was associated with an increased risk of dementia [55, 56]. In WHIMS (Women's Health Initiative Memory Study) [56], this negative signal could be seen as early as 1 year after randomization and may therefore have been captured in short-duration trials, despite the small number of events, if preliminary trials had been conducted.

\subsection{Dose Concerns}

Current models suggest that the rate of change of $\mathrm{AD}$ biomarkers varies across different stages of disease development [23], which may reflect different underlying processes, and since experience from other fields has shown that determining preventive doses may be tricky (for instance, many doses have been used for aspirin in cardiovascular prevention [57]), one can only regret that no specific dose-finding trials have been conducted.

In trials investigating the effect of $\mathrm{AD}$-specific drugs (cholinesterase inhibitors, solanezumab), the doses used in prevention trials were those recommended/tested in $\mathrm{AD}$ treatment (i.e., $400 \mathrm{mg}$ intravenously every 4 weeks for solanezumab).

For other drugs, doses tested in AD prevention were also the ones routinely used for other conditions. Antihypertensive trials are particularly interesting since doses were determined according to the efficacy on blood pressure. However, some evidence suggests that the effect of antihypertensive drugs on $\mathrm{AD}$ prevention may be due to different mechanisms, independent of their blood pressurelowering action $[58,59]$. Thus, doses used in hypertension may not be the most appropriate and subjects in prevention trials could potentially have received lower doses if appropriate phase II trials were conducted. This is of concern since toxicity is almost always dose related and exposing individuals to the minimal effective dose should be a priority. If a beneficial effect were to be found with one dose, approval would probably be granted for that specific dose without testing if lower doses were equally effective.

\subsection{Safety Concerns}

So far, only one candidate drug (solanezumab) has been tested in well-conducted phase III RCTs for sporadic AD prevention without being already approved for another indication. Solanezumab has been used by approximately $1000 \mathrm{AD}$ patients in prior phase III treatment trials [22], and safety findings did not retrieve any signal that met the investigator's pre-specified criteria. An increase in cardiac diseases was nonetheless seen in patients treated with solanezumab compared to those who received the placebo (3.1 vs. $1.6 \%$ ). As opposed to previous findings [60], there was no significant increase in amyloid-related imaging abnormalities with edema or hemorrhage associated with solanezumab in phase III trials [22].

Compared to developing new drugs, testing already approved drugs in new indications may seem relatively safe. Indeed, drugs must have demonstrated a favorable benefit-risk ratio in order to obtain market approval. However, the appreciation of the benefit-risk ratio strongly depends on the context of potential use and transposing benefit-risk ratios found in treatment situations to prevention situations is difficult. Indeed, in mass prevention each individual has only a small expectation of benefit and this small benefit can easily be outweighed by a small risk [61]. Therefore, safety must be a priority in prevention trials. Furthermore, drug safety profiles are likely to be imperfectly known in elderly subjects because phase III developments are usually conducted in younger populations with few elderly people who, furthermore, may be non-representative of subjects of the same age [62, 63].

In various instances, prevention trials of $\mathrm{AD}$ have been halted early for induced harm with long-time approved drugs. ADAPT (Alzheimer's Disease Anti-inflammatory Prevention Trial) (which aimed to study the effect of naproxen and celecoxib to prevent AD) [55] and WHIMS (testing the efficacy of conjugated equine estrogens \pm progestin) [56] were discontinued for cardiovascular harm. One RCT investigated the effect of the blockbuster NSAID rofecoxib [64], which was later withdrawn from the international market due to an increased risk of cardiovascular events. Last, the safety of pioglitazone tested in the very large TOMMOROW trial has been questioned [35, 65] and this antidiabetic drug is no longer marketed in some countries (e.g., France).

Caution should prevail in prevention trials, even with drugs that have been marketed for a long time. Careful assessment of the benefit-risk ratio in the prevention context should be conducted considering the basal AD risk of the included population (i.e., high-risk individuals vs. lowrisk population).

\section{New Directions}

There has been a major shift in the methodology of $\mathrm{AD}$ prevention trials since the results of the first trials were published a little more than 15 years ago [66]. In the late 1990s and early 2000s, trials essentially tested non-ADspecific drugs or re-tested approved AD drugs as 'secondary' prevention strategies. More recently, lifestyle interventions, including multidomain interventions, have prevailed and some have shown promising results [67-71]. Today, with our revised conceptualization of the disease process, and trial design improvements, pharmacological 
interventions are once again being tested. Innovative design features developed for both pharmacological and non-pharmacological prevention trials are discussed below.

\subsection{Endpoints}

Initially, dementia (or, more specifically, AD-type dementia) incidence was generally used as the primary endpoint. Challenges, including large sample sizes and long follow-up periods, and the difficulty in establishing a reliable diagnosis and exact date of occurrence, as well as our increasing understanding of the $\mathrm{AD}$ continuum, meant that later trials primarily aimed to demonstrate improvement (or less decline) on measures of cognitive function. These measures target either specific cognitive domains, particularly memory, or global cognitive function measured by global tests, such as the Mini-Mental State Examination (MMSE), or batteries of multiple cognitive tests. Composite cognitive outcome measures, focusing in particular on memory and executive function, have recently begun to be developed, and constitute the primary outcome measure for several ongoing trials [33, 72-74]. Such measures aim to detect early cognitive changes and essentially serve as surrogate endpoints for AD incidence. However, to date there are only very limited data about trajectories of cognitive decline measured by these composite measures. Further validation is still required, especially in prospective studies, to determine the optimal weighting of the different components, responsiveness, the clinical relevance of cognitive changes on such measures, and whether or not a significant treatment effect would actually translate into a reduction in the number of cases of clinically apparent $\mathrm{AD}[72,75,76]$.

Biomarkers, including plasma and cerebrospinal fluid (CSF) measures of $A \beta$ or tau, and functional, structural and amyloid brain imaging, have also received much attention as endpoints [77]. Several prevention trials have begun to use biomarkers as outcome measures [33, 34, 78-80], but predominantly as secondary rather than primary outcome measures because no AD biomarker has yet been validated as a surrogate endpoint [81, 82].

\subsection{Target Population}

There has also been a shift in target populations. Trials completed so far have included cognitively normal individuals or those with some form of objective cognitive impairment without dementia, e.g., MCI. Furthermore, some trials have targeted individuals with specific risk factors for $\mathrm{AD}$, such as hypertension [83], a family history of $\mathrm{AD}$ [55], poor nutritional status [84], or those with an increased dementia risk score based on several factors [68]. Recent advances in biomarker and imaging techniques have also meant that it is now possible to identify cognitively normal individuals with evidence of brain amyloid, often considered to have 'preclinical' or 'asymptomatic' AD $[85,86]$. Preventive interventions can, therefore, now be tested in pre-dementia stages of $\mathrm{AD}$, which is now widely regarded as 'secondary' or 'tertiary' prevention, depending on whether or not cognitive impairment is also present [19]. The ongoing A4 trial is an example of such a trial [33]. Genetic inclusion criteria may also be used to target individuals at increased risk of AD. The apolipoprotein $\mathrm{E}(A P O E) \varepsilon 4$ allele is the strongest genetic risk factor for sporadic $\mathrm{AD}$ [87], but no prevention trials to our knowledge have so far used APOE-based inclusion criteria. The TOMMOROW trial is developing a new algorithm, based on APOE and TOMM4O genotype and age, for identifying subjects with increased personal risk of developing MCI due to $\mathrm{AD}$ as an enrichment strategy, and only the subjects with the highest risk will receive active treatment [51]. Another trial that will include only APOE $\varepsilon 4$ homozygotes is in the planning stages [100].

\subsection{Novel Trial Designs}

Adaptive trial designs are beginning to be advocated in the AD field [88], based notably on experience from the breast cancer I-SPY 2 (investigation of serial studies to predict your therapeutic response with imaging and molecular analysis 2) trial [89]. These trials aim to be more efficient, more likely to demonstrate a treatment effect if one exists, and/or more informative [90]. They can speed up the process of drug development, e.g., by using stratified trials, testing several different active treatment arms in the same trial, some of which may be discontinued based on the results of pre-defined interim analyses, or combining late phase II and III trials into 'seamless' studies, whilst maintaining scientific and methodological rigor [90]. Adaptive designs are already starting to be used in prevention by industry (NCT01767311 [101]) and the European Prevention of Alzheimer's Dementia (EPAD) consortium, a public-private partnership (http://www. synapse-managers.com/epad/). Such designs could also be applied in earlier-stage prevention trials, but their use in both clinical and preclinical stages of $\mathrm{AD}$ is currently limited by a lack of validated biomarkers. In particular, we do not have a clear and relatively near-term primary endpoint, nor do we have biomarkers able to predict treatment response [88].

$\mathrm{AD}$ is a multifactorial disease and may be a spectrum of neurodegenerative diseases that coexist and are influenced by other co-morbidities, rather than a single entity. Therefore, instead of a 'one size fits all' approach, personalized preventive interventions could also be considered, based on risk profiles that might take into account 
lifestyle factors, co-morbidities, genetics, and/or biomarkers. More work is required to better define and validate such profiles. In such a context, adaptive interventions could be proposed, based not only on an individual's initial risk profile, but also on their response and/or adherence to interventions. Adaptive interventions could include combination therapies combining multiple pharmacological and/or lifestyle interventions [88, 91].

\section{Conclusion}

Using AD-specific drugs to reduce the risk of AD in highrisk individuals is an individual approach to prevention. If we want to prioritize such an approach, the use of novel trial designs could make the drug development process significantly more efficient. However, the use of such strategies is currently limited by a lack of validated predictive and surrogate markers [88]. Intensive collaboration, including the sharing of data, resources, infrastructure and expertise, across the whole scientific community, in both the public and private sectors, will be necessary for progress.

Lower-risk, population-based approaches, e.g., based around lifestyle changes or the treatment of cardiovascular risk factors, are an alternative approach that could provide substantial benefits for the population, but may only have limited benefits for individuals (the so-called 'prevention paradox'). Given the inherent difficulties with both individual and population approaches, as for many diseases, the best chance of preventing $\mathrm{AD}$ is likely to come from a combination of both [92].

\section{Compliance with Ethical Standards}

Funding No funding was received for this work.

Conflicts of interest N. Coley declares no conflicts of interest. A. Gallini is supported by a grant from the French Ministry of Education, Fondation Plan Alzheimer. S. Andrieu has received grants from Beaufour, Lundbeck, Nestlé, and Lilly; consulting fees or honorarium from Beaufour, Esai, Pierre Fabre, Pfizer, Lundbeck, and Lilly, Sanofi, Novartis; fees for participation in review activities from Beaufour, Pierre Fabre, Pfizer, and Lilly; and support for travel and payment for lectures from Beaufour, Esai, Pierre Fabre, Pfizer, Lundbeck, Lilly, and Nestlé.

\section{References}

1. Prince M, Bryce R, Albanese E, Wimo A, Ribeiro W, Ferri CP. The global prevalence of dementia: a systematic review and metaanalysis. Alzheimers Dement. 2013;9(1):63-75 e2.

2. Matthews FE, Arthur A, Barnes LE, Bond J, Jagger C, Robinson $\mathrm{L}$, et al. A two-decade comparison of prevalence of dementia in individuals aged 65 years and older from three geographical areas of England: results of the Cognitive Function and Ageing Study I and II. Lancet. 2013;382(9902):1405-12.

3. Schrijvers EM, Verhaaren BF, Koudstaal PJ, Hofman A, Ikram MA, Breteler MM. Is dementia incidence declining? Trends in dementia incidence since 1990 in the Rotterdam Study. Neurology. 2012;78(19):1456-63.

4. Langa KM. Is the risk of Alzheimer's disease and dementia declining? Alzheimers Res Ther. 2015;7(1):34.

5. Wimo A, Jonsson L, Bond J, Prince M, Winblad B. The worldwide economic impact of dementia 2010. Alzheimers Dement. 2013;9(1):1-11 e3.

6. Querfurth HW, LaFerla FM. Alzheimer's disease. N Engl J Med. 2010;362(4):329-44.

7. Mangialasche F, Solomon A, Winblad B, Mecocci P, Kivipelto M. Alzheimer's disease: clinical trials and drug development. Lancet Neurol. 2010;9(7):702-16.

8. Karran E, Hardy J. A critique of the drug discovery and phase 3 clinical programs targeting the amyloid hypothesis for Alzheimer disease. Ann Neurol. 2014;76(2):185-205.

9. Bezprozvanny I. The rise and fall of Dimebon. Drug News Perspect. 2010;23(8):518-23.

10. Douillet P, Orgogozo JM. What we have learned from the Xaliproden Sanofi-Aventis trials. J Nutr Health Aging. 2009; 13(4):365-6.

11. Feldman HH, Doody RS, Kivipelto M, Sparks DL, Waters DD, Jones RW, et al. Randomized controlled trial of atorvastatin in mild to moderate Alzheimer disease: LEADe. Neurology. 2010;74(12):956-64.

12. Sano M, Bell KL, Galasko D, Galvin JE, Thomas RG, van Dyck $\mathrm{CH}$, et al. A randomized, double-blind, placebo-controlled trial of simvastatin to treat Alzheimer disease. Neurology. 2011; 77(6):556-63.

13. Herrup K, Carrillo MC, Schenk D, Cacace A, Desanti S, Fremeau R et al. Beyond amyloid: getting real about nonamyloid targets in Alzheimer's disease. Alzheimers Dement. 2013;9(4): 452-8 e1.

14. Laske C. Phase 3 trials of solanezumab and bapineuzumab for Alzheimer's disease. N Engl J Med. 2014;370(15):1459.

15. Morris GP, Clark IA, Vissel B. Inconsistencies and controversies surrounding the amyloid hypothesis of Alzheimer's disease. Acta Neuropathol Commun. 2014;2:135.

16. Hefti F, Goure WF, Jerecic J, Iverson KS, Walicke PA, Krafft GA. The case for soluble Abeta oligomers as a drug target in Alzheimer's disease. Trends Pharmacol Sci. 2013;34(5):261-6.

17. Salloway S, Sperling R, Fox NC, Blennow K, Klunk W, Raskind $\mathrm{M}$, et al. Two phase 3 trials of bapineuzumab in mild-to-moderate Alzheimer's disease. N Engl J Med. 2014;370(4):322-33.

18. Hardy J, Bogdanovic N, Winblad B, Portelius E, Andreasen N, Cedazo-Minguez A, et al. Pathways to Alzheimer's disease. J Intern Med. 2014;275(3):296-303.

19. Sperling RA, Jack CR, Jr., Aisen PS. Testing the right target and right drug at the right stage. Sci Transl Med. 2011;3(111): $111 \mathrm{~cm} 33$.

20. Cummings JL, Doody R, Clark C. Disease-modifying therapies for Alzheimer disease: challenges to early intervention. Neurology. 2007;69(16):1622-34.

21. Callaway E. Alzheimer's drugs take a new tack. Nature. 2012;489(7414):13-4.

22. Doody RS, Thomas RG, Farlow M, Iwatsubo T, Vellas B, Joffe $\mathrm{S}$, et al. Phase 3 trials of solanezumab for mild-to-moderate Alzheimer's disease. N Engl J Med. 2014;370(4):311-21.

23. Jack CR Jr, Knopman DS, Jagust WJ, Petersen RC, Weiner MW, Aisen PS, et al. Tracking pathophysiological processes in Alzheimer's disease: an updated hypothetical model of dynamic biomarkers. Lancet Neurol. 2013;12(2):207-16. 
24. Daviglus ML, Bell CC, Berrettini W, Bowen PE, Connolly ES Jr, Cox NJ, et al. National Institutes of Health State-of-theScience Conference statement: preventing Alzheimer disease and cognitive decline. Ann Intern Med. 2010;153(3):176-81.

25. Brookmeyer R, Johnson E, Ziegler-Graham K, Arrighi HM. Forecasting the global burden of Alzheimer's disease. Alzheimers Dement. 2007;3(3):186-91.

26. Williams JW, Plassman BL, Burke J, Benjamin S. Preventing Alzheimer's disease and cognitive decline. Evid Rep Technol Assess (Full Rep). 2010;193:1-727.

27. Doody RS, Ferris SH, Salloway S, Sun Y, Goldman R, Watkins WE, et al. Donepezil treatment of patients with MCI: a 48-week randomized, placebo-controlled trial. Neurology. 2009;72(18): 1555-61.

28. Petersen RC, Thomas RG, Grundman M, Bennett D, Doody R, Ferris $\mathrm{S}$, et al. Vitamin $\mathrm{E}$ and donepezil for the treatment of mild cognitive impairment. N Engl J Med. 2005;352(23):2379-88.

29. Salloway S, Ferris S, Kluger A, Goldman R, Griesing T, Kumar $\mathrm{D}$, et al. Efficacy of donepezil in mild cognitive impairment: a randomized placebo-controlled trial. Neurology. 2004;63(4): 651-7.

30. Feldman HH, Ferris S, Winblad B, Sfikas N, Mancione L, He Y, et al. Effect of rivastigmine on delay to diagnosis of Alzheimer's disease from mild cognitive impairment: the InDDEx study. Lancet Neurol. 2007;6(6):501-12.

31. Peters O, Lorenz D, Fesche A, Schmidtke K, Hull M, Perneczky $\mathrm{R}$, et al. A combination of galantamine and memantine modifies cognitive function in subjects with amnestic MCI. J Nutr Health Aging. 2012;16(6):544-8.

32. Winblad B, Gauthier S, Scinto L, Feldman H, Wilcock GK, Truyen L, et al. Safety and efficacy of galantamine in subjects with mild cognitive impairment. Neurology. 2008;70(22): 2024-35.

33. Sperling RA, Rentz DM, Johnson KA, Karlawish J, Donohue M, Salmon DP et al. The A4 study: stopping AD before symptoms begin? Sci Transl Med. 2014;6(228):228fs13.

34. Mills SM, Mallmann J, Santacruz AM, Fuqua A, Carril M, Aisen PS, et al. Preclinical trials in autosomal dominant AD: implementation of the DIAN-TU trial. Rev Neurol (Paris). 2013;169(10):737-43.

35. Neumann A, Weill A, Ricordeau P, Fagot JP, Alla F, Allemand H. Pioglitazone and risk of bladder cancer among diabetic patients in France: a population-based cohort study. Diabetologia. 2012;55(7):1953-62.

36. Rouch L, Cestac P, Hanon O, Cool C, Helmer C, Bouhanick B, et al. Antihypertensive drugs, prevention of cognitive decline and dementia: a systematic review of observational studies, randomized controlled trials and meta-analyses, with discussion of potential mechanisms. CNS Drugs. 2015;29(2):113-30.

37. Khachaturian AS, Zandi PP, Lyketsos CG, Hayden KM, Skoog I, Norton MC, et al. Antihypertensive medication use and incident Alzheimer disease: the Cache County Study. Arch Neurol. 2006;63(5):686-92.

38. O'Brien J, Jackson JW, Grodstein F, Blacker D, Weuve J. Postmenopausal hormone therapy is not associated with risk of all-cause dementia and Alzheimer's disease. Epidemiol Rev. 2014;36:83-103.

39. Zandi PP, Carlson MC, Plassman BL, Welsh-Bohmer KA, Mayer LS, Steffens DC, et al. Hormone replacement therapy and incidence of Alzheimer disease in older women: the Cache County Study. JAMA. 2002;288(17):2123-9.

40. Szekely CA, Thorne JE, Zandi PP, Ek M, Messias E, Breitner $\mathrm{JC}$, et al. Nonsteroidal anti-inflammatory drugs for the prevention of Alzheimer's disease: a systematic review. Neuroepidemiology. 2004;23(4):159-69.
41. Etminan M, Gill S, Samii A. Effect of non-steroidal anti-inflammatory drugs on risk of Alzheimer's disease: systematic review and meta-analysis of observational studies. BMJ. 2003;327(7407):128.

42. Richardson K, Schoen M, French B, Umscheid CA, Mitchell MD, Arnold SE, et al. Statins and cognitive function: a systematic review. Ann Intern Med. 2013;159(10):688-97.

43. Muangpaisan W, Brayne C. Systematic review of statins for the prevention of vascular dementia or dementia. Geriatr Gerontol Int. 2010;10(2):199-208.

44. McGuinness B, Craig D, Bullock R, Passmore P. Statins for the prevention of dementia. Cochrane Database Syst Rev. 2009;2:CD003160.

45. Heneka MT, Fink A, Doblhammer G. Effect of pioglitazone medication on the incidence of dementia. Ann Neurol. doi:10. 1002/ana.24439 (Epub 2015 May 14).

46. Tzourio C, Anderson C, Chapman N, Woodward M, Neal B, MacMahon S, et al. Effects of blood pressure lowering with perindopril and indapamide therapy on dementia and cognitive decline in patients with cerebrovascular disease. Arch Intern Med. 2003;163(9):1069-75.

47. Forette F, Seux ML, Staessen JA, Thijs L, Birkenhager WH, Babarskiene MR, et al. Prevention of dementia in randomised double-blind placebo-controlled Systolic Hypertension in Europe (Syst-Eur) trial. Lancet. 1998;352(9137):1347-51.

48. Wharton W, Gleason CE, Miller VM, Asthana S. Rationale and design of the Kronos Early Estrogen Prevention Study (KEEPS) and the KEEPS Cognitive and Affective sub study (KEEPS Cog). Brain Res. 2013;1514:12-7.

49. Study design of ASPirin in Reducing Events in the Elderly (ASPREE): a randomized, controlled trial. Contemp Clin Trials. 2013;36(2):555-64.

50. Kandiah N, Feldman HH. Therapeutic potential of statins in Alzheimer's disease. J Neurol Sci. 2009;283(1-2):230-4.

51. Crenshaw DG, Gottschalk WK, Lutz MW, Grossman I, Saunders AM, Burke JR, et al. Using genetics to enable studies on the prevention of Alzheimer's disease. Clin Pharmacol Ther. 2013;93(2):177-85.

52. Landreth G, Jiang Q, Mandrekar S, Heneka M. PPARgamma agonists as therapeutics for the treatment of Alzheimer's disease. Neurotherapeutics. 2008;5(3):481-9.

53. Nicolakakis N, Hamel E. The nuclear receptor PPARgamma as a therapeutic target for cerebrovascular and brain dysfunction in Alzheimer's disease. Front Aging Neurosci. 2010;2:21. doi:10. 3389/fnagi.2010.00021.

54. Coley N, Andrieu S, Gardette V, Gillette-Guyonnet S, Sanz C, Vellas B, et al. Dementia prevention: methodological explanations for inconsistent results. Epidemiol Rev. 2008;30:35-66.

55. Lyketsos CG, Breitner JC, Green RC, Martin BK, Meinert C, Piantadosi S, et al. Naproxen and celecoxib do not prevent AD in early results from a randomized controlled trial. Neurology. 2007;68(21):1800-8.

56. Shumaker SA, Legault C, Rapp SR, Thal L, Wallace RB, Ockene JK, et al. Estrogen plus progestin and the incidence of dementia and mild cognitive impairment in postmenopausal women: the Women's Health Initiative Memory Study: a randomized controlled trial. JAMA. 2003;289(20):2651-62.

57. Campbell CL, Smyth S, Montalescot G, Steinhubl SR. Aspirin dose for the prevention of cardiovascular disease: a systematic review. JAMA. 2007;297(18):2018-24.

58. Ashby EL, Kehoe PG. Current status of renin-aldosterone angiotensin system-targeting anti-hypertensive drugs as therapeutic options for Alzheimer's disease. Expert Opin Investig Drugs. 2013;22(10):1229-42. 
59. Goodison WV, Frisardi V, Kehoe PG. Calcium channel blockers and Alzheimer's disease: potential relevance in treatment strategies of metabolic syndrome. $\mathrm{J}$ Alzheimers Dis. 2012;30(Suppl 2):S269-82.

60. Sperling RA, Jack CR Jr, Black SE, Frosch MP, Greenberg SM, Hyman BT, et al. Amyloid-related imaging abnormalities in amyloid-modifying therapeutic trials: recommendations from the Alzheimer's Association Research Roundtable Workgroup. Alzheimers Dement. 2011;7(4):367-85.

61. Rose G. Strategy of prevention: lessons from cardiovascular disease. Br Med J (Clin Res Ed). 1981;282(6279):1847-51.

62. Golomb BA, Chan VT, Evans MA, Koperski S, White HL, Criqui $\mathrm{MH}$. The older the better: are elderly study participants more non-representative? A cross-sectional analysis of clinical trial and observational study samples. BMJ Open. 2012;2(6):e000833. doi:10.1136/bmjopen-2012-000833.

63. Herrera AP, Snipes SA, King DW, Torres-Vigil I, Goldberg DS, Weinberg AD. Disparate inclusion of older adults in clinical trials: priorities and opportunities for policy and practice change. Am J Public Health. 2010;100(Suppl 1):S105-12.

64. Thal LJ, Ferris SH, Kirby L, Block GA, Lines CR, Yuen E, et al. A randomized, double-blind, study of rofecoxib in patients with mild cognitive impairment. Neuropsychopharmacology. 2005; 30(6):1204-15.

65. Azoulay L, Yin H, Filion KB, Assayag J, Majdan A, Pollak MN, et al. The use of pioglitazone and the risk of bladder cancer in people with type 2 diabetes: nested case-control study. BMJ. 2012;344:e3645.

66. Andrieu S, Coley N, Aisen P, Carrillo MC, DeKosky S, Durga J, et al. Methodological issues in primary prevention trials for neurodegenerative dementia. J Alzheimers Dis. 2009;16(2): 235-70.

67. Lautenschlager NT, Cox KL, Flicker L, Foster JK, van Bockxmeer FM, Xiao J, et al. Effect of physical activity on cognitive function in older adults at risk for Alzheimer disease: a randomized trial. JAMA. 2008;300(9):1027-37.

68. Ngandu T, Lehtisalo J, Solomon A, Levalahti E, Ahtiluoto S, Antikainen R, et al. A 2 year multidomain intervention of diet, exercise, cognitive training, and vascular risk monitoring versus control to prevent cognitive decline in at-risk elderly people (FINGER): a randomised controlled trial. Lancet. 2015;385 (9984):2255-63.

69. Willis SL, Tennstedt SL, Marsiske M, Ball K, Elias J, Koepke $\mathrm{KM}$, et al. Long-term effects of cognitive training on everyday functional outcomes in older adults. JAMA. 2006;296(23): 2805-14.

70. Wolinsky FD, Vander Weg MW, Howren MB, Jones MP, Dotson MM. A randomized controlled trial of cognitive training using a visual speed of processing intervention in middle aged and older adults. PLoS One. 2013;8(5):e61624.

71. Yurko-Mauro K, McCarthy D, Rom D, Nelson EB, Ryan AS, Blackwell A, et al. Beneficial effects of docosahexaenoic acid on cognition in age-related cognitive decline. Alzheimers Dement. 2010;6(6):456-64.

72. Donohue MC, Sperling RA, Salmon DP, Rentz DM, Raman R, Thomas RG, et al. The Preclinical Alzheimer cognitive composite: measuring amyloid-related decline. JAMA Neurol. 2014;71(8):961-70.

73. Ayutyanont N, Langbaum JB, Hendrix SB, Chen K, Fleisher AS, Friesenhahn M, et al. The Alzheimer's prevention initiative composite cognitive test score: sample size estimates for the evaluation of preclinical Alzheimer's disease treatments in presenilin 1 E280A mutation carriers. J Clin Psychiatry. 2014;75(6):652-60.

74. Langbaum JB, Hendrix SB, Ayutyanont N, Chen K, Fleisher AS, Shah RC, et al. An empirically derived composite cognitive test score with improved power to track and evaluate treatments for preclinical Alzheimer's disease. Alzheimers Dement. 2014;10(6):666-74.

75. Amariglio RE, Donohue MC, Marshall GA, Rentz DM, Salmon DP, Ferris SH, et al. Tracking early decline in cognitive function in older individuals at risk for Alzheimer disease dementia: the Alzheimer's disease cooperative study cognitive function instrument. JAMA Neurol. 2015;72(4):446-54.

76. Kryscio RJ. Secondary prevention trials in Alzheimer disease: the challenge of identifying a meaningful end point. JAMA Neurol. 2014;71(8):947-9.

77. Hampel H, Wilcock G, Andrieu S, Aisen P, Blennow K, Broich $\mathrm{K}$, et al. Biomarkers for Alzheimer's disease therapeutic trials. Prog Neurobiol. 2011;95(4):579-93.

78. Vellas B, Carrie I, Gillette-Guyonnet S, Touchon J, Dantoine T, Dartigues JF, et al. MAPT study: a multidomain approach for preventing Alzheimer's disease: design and baseline data. J Prev Alz Dis. 2014;1(1):13-22.

79. Smith AD, Smith SM, de Jager CA, Whitbread P, Johnston C, Agacinski G, et al. Homocysteine-lowering by $\mathrm{B}$ vitamins slows the rate of accelerated brain atrophy in mild cognitive impairment: a randomized controlled trial. PLoS One. 2010;5(9): e12244.

80. Kivipelto M, Solomon A, Ahtiluoto S, Ngandu T, Lehtisalo J, Antikainen R, et al. The Finnish Geriatric Intervention Study to Prevent Cognitive Impairment and Disability (FINGER): study design and progress. Alzheimers Dement. 2013;9(6):657-65.

81. Coley N, Andrieu S, Delrieu J, Voisin T, Vellas B. Biomarkers in Alzheimer's disease: not yet surrogate endpoints. Ann N Y Acad Sci. 2009;1180:119-24.

82. Sperling R, Mormino E, Johnson K. The evolution of preclinical Alzheimer's disease: implications for prevention trials. Neuron. 2014;84(3):608-22.

83. Peters R, Beckett N, Forette F, Tuomilehto J, Clarke R, Ritchie $\mathrm{C}$, et al. Incident dementia and blood pressure lowering in the Hypertension in the Very Elderly Trial cognitive function assessment (HYVET-COG): a double-blind, placebo controlled trial. Lancet Neurol. 2008;7(8):683-9.

84. McMahon JA, Green TJ, Skeaff CM, Knight RG, Mann JI, Williams SM. A controlled trial of homocysteine lowering and cognitive performance. N Engl J Med. 2006;354(26):2764-72.

85. Sperling RA, Karlawish J, Johnson KA. Preclinical Alzheimer disease-the challenges ahead. Nat Rev Neurol. 2013;9(1):54-8.

86. Sperling RA, Aisen PS, Beckett LA, Bennett DA, Craft S, Fagan AM, et al. Toward defining the preclinical stages of Alzheimer's disease: recommendations from the National Institute on AgingAlzheimer's Association workgroups on diagnostic guidelines for Alzheimer's disease. Alzheimers Dement. 2011;7(3): 280-92.

87. Corder EH, Saunders AM, Strittmatter WJ, Schmechel DE, Gaskell PC, Small GW, et al. Gene dose of apolipoprotein E type 4 allele and the risk of Alzheimer's disease in late onset families. Science. 1993;261(5123):921-3.

88. Stephenson D, Perry D, Bens C, Bain LJ, Berry D, Krams M, et al. Charting a path toward combination therapy for Alzheimer's disease. Expert Rev Neurother. 2015;15(1):107-13.

89. Barker AD, Sigman CC, Kelloff GJ, Hylton NM, Berry DA, Esserman LJ. I-SPY 2: an adaptive breast cancer trial design in the setting of neoadjuvant chemotherapy. Clin Pharmacol Ther. 2009;86(1):97-100.

90. Food and Drug Administration. Guidance for industry: adaptive design clinical trials for drugs and biologics. Draft guidance. Maryland: FDA; 2010.

91. Cedernaes J, Schioth HB, Benedict C. Efficacy of antibodybased therapies to treat Alzheimer's disease: just a matter of timing? Exp Gerontol. 2014;57:104-6. 
92. Rose G. Sick individuals and sick populations. Int J Epidemiol. 1985;14(1):32-8.

93. Hajjar I, Hart M, Chen YL, Mack W, Milberg W, Chui H, et al. Effect of antihypertensive therapy on cognitive function in early executive cognitive impairment: a double-blind randomized clinical trial. Arch Intern Med. 2012;172(5):442-4.

94. Shumaker SA, Legault C, Kuller L, Rapp SR, Thal L, Lane DS, et al. Conjugated equine estrogens and incidence of probable dementia and mild cognitive impairment in postmenopausal women: Women's Health Initiative Memory Study. JAMA. 2004;291(24):2947-58.

95. Tierney MC, Oh P, Moineddin R, Greenblatt EM, Snow WG, Fisher RH, et al. A randomized double-blind trial of the effects of hormone therapy on delayed verbal recall in older women. Psychoneuroendocrinology. 2009;34(7):1065-74.

96. Gomez-Isla T, Blesa R, Boada M, Clarimon J, Del Ser T, Domenech $\mathrm{G}$, et al. A randomized, double-blind, placebo controlled-trial of triflusal in mild cognitive impairment: the TRIMCI study. Alzheimer Dis Assoc Disord. 2008;22(1):21-9.

97. University of Washington, Seattle Institute for Biomedical and Clinical Research, VA Puget Sound Health Care System. Effects of simvastatin on biomarkers (SimBio) [ClinicalTrials.gov identifier NCT01142336]. US National Institutes of Health, ClinicalTrials.gov. http://www.clinicaltrials.gov. Accessed 28 Jun 2015.

98. Charite University, Berlin, Germany, German Federal Ministry of Education and Research. Trial of simvastatin in amnestic mild cognitive impairment (MCI) patients (SIMaMCI) [ClinicalTrials.gov identifier NCT00842920]. US National Institutes of Health, ClinicalTrials.gov. http://www.clinicaltrials.gov. Accessed 28 Jun 2015.

99. University of Wisconsin-Madison. Statin effects on beta-amyloid and cerebral perfusion in adults at risk for Alzheimer's disease (SHARP) [ClinicalTrials.gov identifier NCT00939822]. US National Institutes of Health, ClinicalTrials.gov. http://www. clinicaltrials.gov. Accessed 28 Jun 2015.

100. Banner Alzheimer's Institute. Alzheimer's Prevention Initiative. http://banneralz.org/research-plus-discovery/alzheimers-preventioninitiative.aspx. Accessed 1 July 2015.

101. Eisai Inc. A study to evaluate safety, tolerability, and efficacy of BAN2401 in subjects with early Alzheimer's disease [ClinicalTrials.gov identifier NCT01767311]. US National Institutes of Health, ClinicalTrials.gov. http://www.clinicaltrials.gov. Accessed 28 Jun 2015. 